\title{
Field testing of an innovative data collection tool in India reveals that over $30 \%$ of individuals chew betel nut
}

Matt Lechner ${ }^{1,2,3^{*}}$, Helen Hudson ${ }^{1^{*}}$, Charles E. Breeze ${ }^{1^{*}}$, Wendell G. Yarbrough ${ }^{4,5}$, Dheeraj Kumbhar ${ }^{6}$, Bhik Kotecha ${ }^{2,7}$, Francis M. Vaz', Valerie J. Lund ${ }^{3,7}$, Vaijayanti Pethe ${ }^{6}$, Dhananjay Kelkar6 \& Paul O'Flynn ${ }^{3}$

1 UCL Cancer Institute, University College London, 72 Huntley Street, London, WC1E 6DD, United Kingdom. Barts Health NHS Trust, London, UK

${ }^{3}$ Head and Neck Centre, University College London Hospitals NHS Trust, Euston Road, London, NW1 2PG, United Kingdom. ${ }^{4}$ Molecular Virology Program, Yale Cancer Center, Yale School of Medicine, New Haven, Connecticut, US

${ }^{5}$ Department of Surgery, Division of Otolaryngology, Yale School of Medicine, New Haven, Connecticut, US

6 Department of Otolaryngology, Deenanath Mangeshkar Hospital, Pune, India

7 Royal National Throat, Nose and Ear Hospital, University College London Hospitals NHS Trust, 330 Grays Inn Road, London, WC1X 8DA, United Kingdom.

* Contributed equally

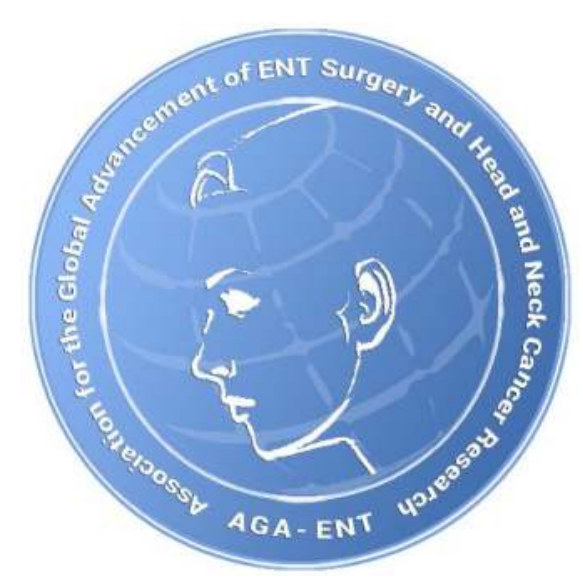

www.aga-ent.org
Background: At least $10 \%$ of the world population chews betel nut on a regular basis. India is not only the largest consumer of betel nut but also has the highest incidence of oral cancer cases worldwide. ${ }^{1,2,3}$ Objectives: (1) To obtain prevalence data on betel nut chewing and tobacco chewing in India and on the population's knowledge of the carcinogenicity of betel nut; (2) to raise awareness of oral cancer.

Methods: Data was collected from 1049 members of the public using an anonymous cross-sectional questionnaire within the BICRAA app 4 in India.

Results: $31.5 \%$ of people participating in this survey report that they chew betel nut on a regular basis (95\%Cl: 28.72-34.38\%). Betel nut consumers are less aware that betel nut causes cancer $(P=2.314 \mathrm{e}-07)$ and more likely to chew tobacco $(P<2.2 \mathrm{e}-16)$.

Conclusions: Betel nut consumers are less aware that betel nut causes cancer, showing a potential for awareness campaigns.
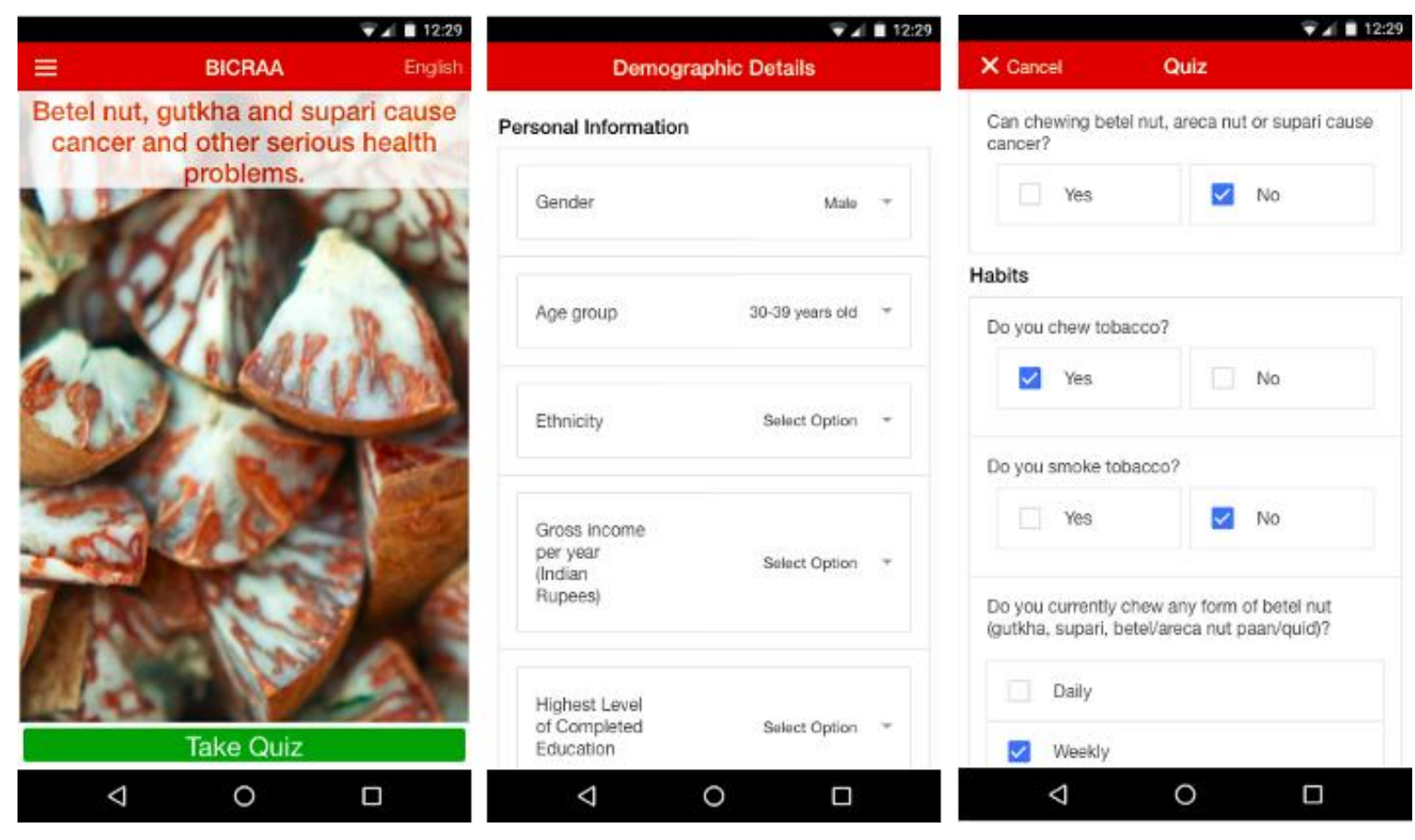

Figure 1: BICRAA app: home screen and survey

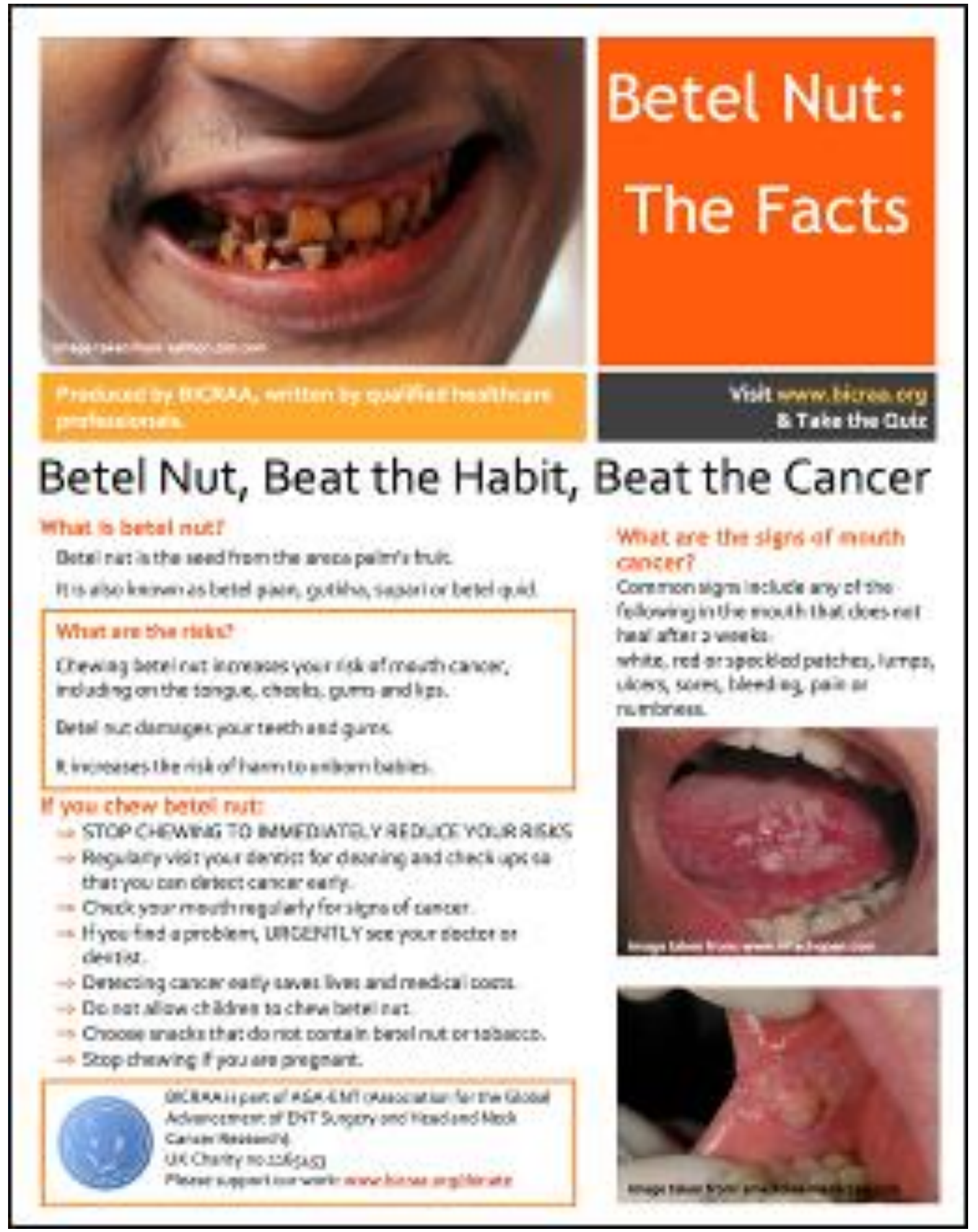

Figure 2: English version of the Betel Nut Facts Leaflet that was distributed during the awareness campaign 